\title{
A Predominant Reversal in the Relationship between the SAM and East Antarctic Temperatures during the Twenty-First Century
}

\author{
Gareth J. Marshall, Andrew OrR, And John Turner \\ British Antarctic Survey, Natural Environment Research Council, Cambridge, United Kingdom
}

(Manuscript received 24 September 2012, in final form 18 January 2013)

\begin{abstract}
The scientific literature portrays a temporally invariant spatial relationship between the phase of the southern annular mode (SAM) and the sign of surface air temperature (SAT) anomalies across Antarctica. However, here the authors describe a predominant switch from a negative to positive SAM-temperature relationship (STR) across East Antarctica in austral summer/autumn during the first decade of the twentyfirst century, when the SAM was generally weakly positive. Of the nine years that had a positive regional STR from 1957 to 2010, seven occurred during the last decade. This reversal appears to be a response to anomalous high pressure over East Antarctica, resulting from variability in the phase and amplitude of the local component of the zonal wavenumber 3 pressure pattern. In years when a reversed (positive) regional STR exists the anomalous circulation is such that there is greater energy flux into the region, while enhanced katabatic drainage across the continental interior disrupts the surface temperature inversion leading to warmer SATs inland, too. The average summer/autumn SAT increase across East Antarctica for years with reversed versus standard STR is $\sim 1^{\circ} \mathrm{C}$. Anthropogenically forced models fail to reproduce the trend toward the anomalous high pressure pattern so it is likely that the STR switch is due to natural internal climate variability. That such broadscale STR reversals can take place on decadal time scales needs to be considered when detecting and attributing recent Antarctic climate change and when utilizing isotope data from the East Antarctic ice core record to provide a proxy SAM index prior to the instrumental record.
\end{abstract}

\section{Introduction}

Thompson and Solomon (2002, hereafter TS02) were the first to demonstrate a strong relationship between the southern annular mode (SAM), the principal mode of atmospheric circulation variability in the Southern Hemisphere ( $\mathrm{SH}$ ) extratropics, and surface temperatures recorded at Antarctic meteorological stations. The SAM, which has a spatial structure comprising synchronous pressure anomalies of opposite sign in $\mathrm{SH}$ mid- and high latitudes, is considered positive (negative) when pressures are below (above) average over Antarctica. When the SAM is positive the enhanced meridional pressure gradient results in stronger circumpolar westerly winds over the Southern Ocean around Antarctica: conversely, weaker westerlies occur when the SAM is negative. For a $22-\mathrm{yr}$ period

Corresponding author address: Gareth Marshall, British Antarctic Survey, Natural Environment Research Council, High Cross, Madingley Road, Cambridge CB3 0ET, United Kingdom.

E-mail: gjma@bas.ac.uk
(1979-2000), during which a positive SAM dominated, TS02 described a distinct spatial pattern of temperature change across the Antarctic continent, characterized by warming in the Antarctic Peninsula and cooling across East Antarctica. Satellite data revealed that the latter was also the case across much of West Antarctica during this period (Kwok and Comiso 2002; Schneider et al. 2004), where there are no long-term Antarctic stations. Although TS02 limited their analysis to austral summer and autumn (December-May), Marshall (2007) showed that this negative spatial SAM-temperature relationship (STR) was generally consistent across all four seasons in East Antarctica for 1957-2004, with the majority of the regional STR being statistically significant at $<1 \%$ level. He also indicated that, based on running 20 -yr windows, there had been no significant change in the sign or magnitude of the STR at Mawson (a coastal East Antarctic station; cf. Fig. 1) since the 1950s.

Using model data, van den Broeke and van Lipzig (2003) showed that there are two principal processes responsible for this negative STR. First, the stronger circumpolar westerly winds during a positive SAM tend 


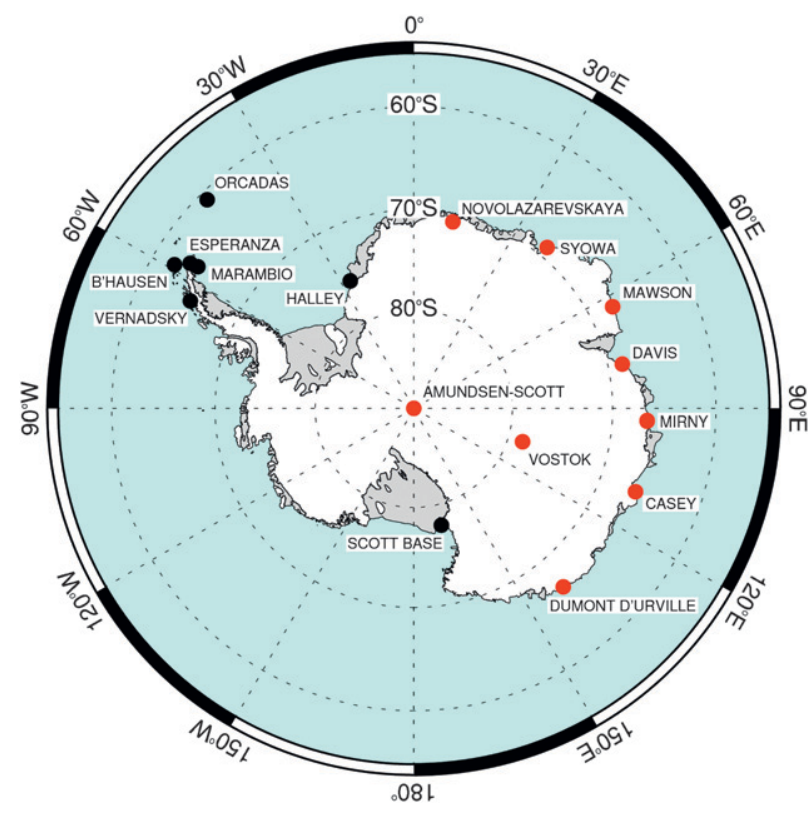

FIG. 1. Location map of the Antarctic meteorological stations used in this study. The nine stations shown with a red dot are used to produce the index of normalized East Antarctic SAT.

to isolate East Antarctica, leading to a reduction in meridional advection (of heat) into the continent. Second, the easterlies that dominate the East Antarctic near-surface circulation, which result from both katabatic drainage and adjustment to large-scale horizontal pressure gradients (e.g., Parish and Bromwich 2007), are weakened over much of the continent. This reduces turbulent heat flow toward the surface and hence leads to a reduction in surface potential temperature, resulting in a stronger surface inversion and cooler surface temperatures.

The SAM has shown a statistically significant positive trend in both austral summer (December-February) and austral autumn (March-May) over recent decades (e.g., Marshall 2007). This trend in the SAM has been linked to anthropogenic forcing, specifically ozone depletion and, to a lesser extent, greenhouse gas increases (e.g., Thompson et al. 2011 and references therein). A SAM reconstruction back to the late nineteenth century (Fogt et al. 2009) indicates that the recent summer trend is unprecedented while similar trends in autumn may have occurred previously, suggesting that this recent autumn trend may be simply natural climate variability. By removing the temperature trends congruent with the SAM, Gillett et al. (2008) revealed a residual warming across most of the Antarctic continent. This implies that the cooling effect of the combination of positive SAM trends and negative regional STR has been "shielding" East Antarctica from the impact of "global warming."
Based on calculated regression coefficients, Marshall (2007) estimated that for 1957-2004 this SAM-related cooling exceeded $1{ }^{\circ} \mathrm{C}$ in autumn at the majority of East Antarctic stations. The cooling was approximately half that value in summer, although the SAM contributed a higher proportion of the observed change in this season.

In this paper we update the work of TS02 and Marshall (2007) to include the first decade of the twentyfirst century and attempt to explain the observed reversal in the sign of the East Antarctic STR that dominates during this period. There is evidence of local STR reversals across Antarctica (Silvestri and Vera 2009; Marshall et al. 2011), but this paper represents the first to document this phenomenon across an entire region of the continent. Its significance lies in the fact that it demonstrates that the assumed paradigm of a consistent spatial pattern of STR across Antarctica, as described in TS02 and papers since, is incorrect. That such broadscale reversals can take place on decadal time scales needs to be accounted for when detecting and attributing climate change, as well as when utilizing isotope data derived from the Antarctic ice core record to provide a proxy SAM index prior to the beginning of the instrumental record (e.g., Schneider et al. 2006).

\section{Data and methodology}

\section{a. The SAM index}

We use the monthly SAM index developed by Marshall (2003), starting in 1957 and updated to 2010. This is based on mean sea level pressure data from 12 meteorological stations, six located at $\sim 40^{\circ} \mathrm{S}$ and a further six at $\sim 65^{\circ} \mathrm{S}$. The value of the SAM is calculated as the normalized difference between the average station pressure at $40^{\circ} \mathrm{S}$ and $65^{\circ} \mathrm{S}$. Although alternative SAM indices are available, based on the leading empirical orthogonal function (EOF) derived from gridded reanalyses, these datasets have significant errors at southern high latitudes prior to the assimilation of satellite sounder data over the Southern Ocean beginning in the late 1970s (e.g., Bromwich and Fogt 2004). Moreover, Jones et al. (2009) demonstrated that the station-based and EOF-based seasonal SAM indices are closely correlated for the recent period of overlap. (The SAM index utilized here is available online at http://www.antarctica. ac.uk/met/gjma/sam.html and is updated monthly.)

\section{b. In situ meteorological temperature data}

We use monthly temperature records from 15 Antarctic stations (Fig. 1), which are taken primarily from the Scientific Committee on Antarctic Research (SCAR) 
Reference Antarctic Data for Environmental Research (READER) project (Turner et al. 2004). This produced a definitive set of monthly mean values of basic meteorological parameters derived from 6-hourly data where available. (The READER data are available online at http://www.antarctica.ac.uk/met/READER/.)

\section{c. Gridded reanalysis data}

We utilize data from the European Centre for MediumRange Weather Forecasts (ECMWF) Re-Analysis (ERA) Interim product (ERA-Interim; Dee et al. 2011). Compared to earlier reanalyses, this benefits from using a 12-h four-dimensional variational data assimilation (4DVAR) scheme, similar to the latest numerical weather prediction models, and a higher spatial resolution. Particular improvements over the previous 40-yr ECMWF Re-Analysis (ERA-40) include the representation of the hydrological cycle, the quality of the stratospheric circulation and the temporal consistency of the reanalyzed fields. Recent studies (e.g., Bromwich et al. 2011; Bracegirdle and Marshall 2012) have concluded that ERA-Interim is the reanalysis that best represents the climate of the southern high latitudes. Except for the calculation of the meridional energy flux (see section 2e), we use data obtained on a Gaussian N80 grid, which has a spatial resolution of $\sim 125 \mathrm{~km}$, and at standard pressure levels.

\section{d. Statistical methodology}

Correlations are derived using detrended data, a methodology that assumes no link between any linear trends in the predictor (SAM) and predicted (temperature). This estimate of the correlation will give slightly stronger (weaker) values than using raw data for regions that have a negative (positive) STR. The effects of autocorrelation are accounted for when calculating the statistical significance of any relationship (e.g., Santer et al. 2000). The significance of differences between two samples is computed using standard two-tailed $t$-test methodology.

\section{e. Calculation of meridional energy flux}

Following studies such as Genthon and Krinner (1998), the total meridional energy flux $F_{\text {WALL }}$ into the Antarctic across the $60^{\circ} \mathrm{S}$ latitude circle is computed from ERA-Interim data retrieved at a resolution of $2^{\circ} \times$ $2^{\circ}$ and at standard pressure levels from 1000 to $10 \mathrm{hPa}$ (note that this latitude circle encircles Antarctica without intersecting its topography). The total energy in the atmosphere (also known as the moist static energy) comprises contributions from sensible heat $\left(c_{p} T\right)$, latent heat $(L q)$, geopotential energy $(\Phi)$, and kinetic energy $(k)$, where $T$ is the temperature, $q$ is the specific humidity, $\Phi$ is the geopotential, $c_{p}$ is the specific heat at constant pressure $\left(1005.7 \mathrm{~J} \mathrm{~K}^{-1} \mathrm{~kg}^{-1}\right)$, and $L$ is the latent heat of evaporation $\left(2.501 \times 10^{6} \mathrm{~J} \mathrm{~kg}^{-1}\right)$. Hence, $F_{\mathrm{WALL}}$ is given as $v\left(c_{p} T+L q+\Phi\right)$, where $v$ is the meridional wind component and the contribution from kinetic energy is ignored because it is comparatively small. Note that here $F_{\mathrm{WALL}}$ is defined to be positive when the flux of energy is poleward.

\section{Results}

In Fig. 2a we reproduce a version of the bottom-left panel of Fig. 3 of TS02, which shows the decadal change in summer/autumn (December-May) surface air temperature (SAT) at Antarctic stations for the 1969-2000 period (32 yr), as derived from the linear least squares regression line, with the year referring to the December. The trends are negative for East Antarctica and positive for the Antarctic Peninsula, with the greatest cooling of $-0.51^{\circ} \mathrm{C} \mathrm{decade}{ }^{-1}$ at Amundsen-Scott and the largest warming at Marambio $\left(+0.63^{\circ} \mathrm{C}\right.$ decade $\left.^{-1}\right)$. Statistically significant SAT changes are limited to the Antarctic Peninsula. In Fig. $2 b$ the analysis period has been extended by a decade to 1969-2010 (42 yr). We note that the magnitude of the decadal SAT change over the longer period is smaller among all East Antarctic stations (not always apparent in the plot because of the scale used) and that at the two plateau stations, Amundsen-Scott and Vostok, there has been a switch from a negative to a positive SAT trend. Although these results are only applicable to the station data, and there are large regions of East Antarctica where no station data exist, satellite data have shown that monthly SAT anomalies are usually broadly homogeneous across the region (Comiso 2000).

Figure 3 shows a time series of the normalized summer/ autumn East Antarctic SAT anomaly for 1957-2010, based on the nine stations that are shown as red in Fig. 1. This was calculated as the mean of the normalized SAT anomaly time series for each station, against a base period of 1971-2000, to account for the differing magnitude of SAT variability across the stations. These stations were chosen on the basis that they have an STR that is statistically significant at $<1 \%$ level in both summer and autumn (cf. Fig. 2 of Marshall 2007). The mean standard deviation between the normalized anomalies of the nine stations for this 54 -yr period is 0.16 . As expected from the observed reduction or reversal of the negative summer/autumn East Antarctic SAT trends between Figs. 2a and 2b, the last decade has generally shown positive regional SAT anomalies, such that observations do not demonstrate a significant cooling over the region as a whole. This is signified by 

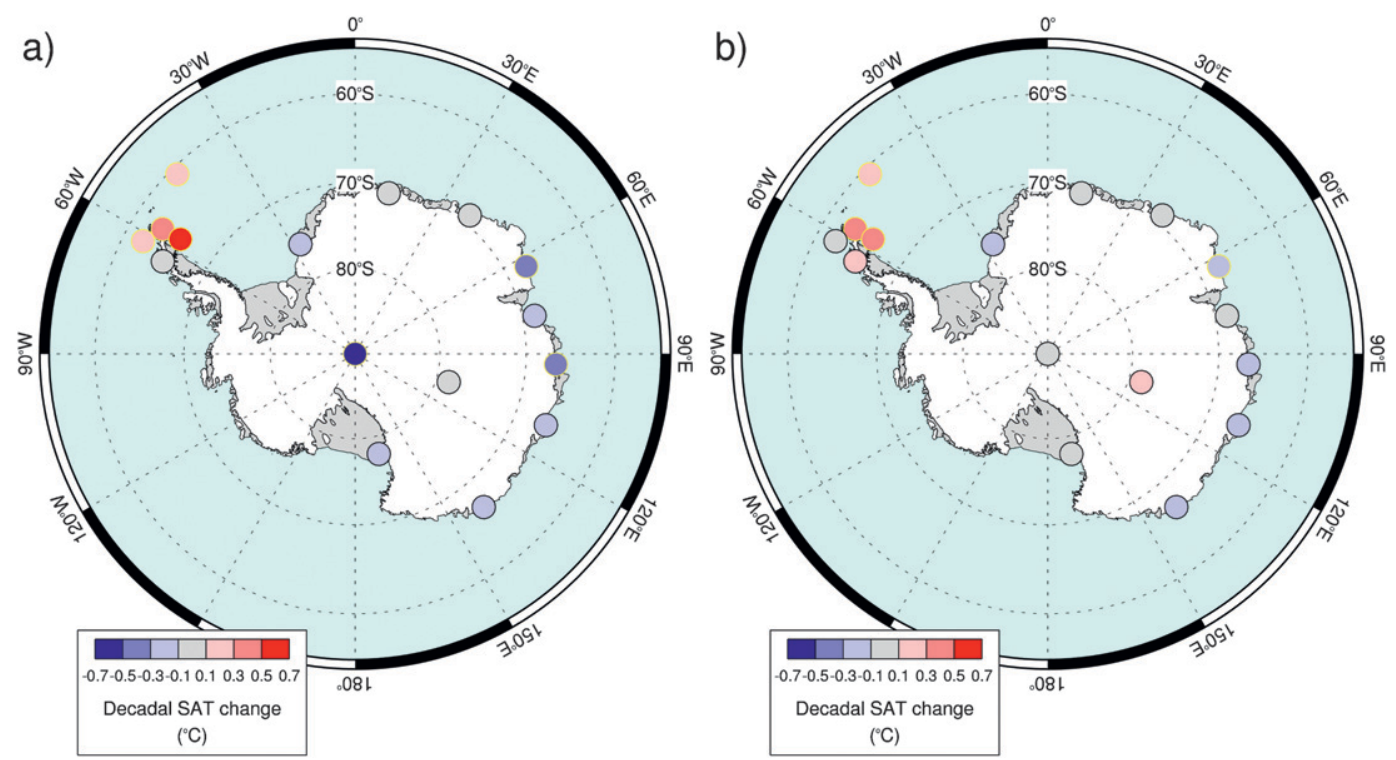

FIG. 2. Decadal SAT change at Antarctic stations for the six month summer/autumn (December-May) period for (a) 1969-2000 and (b) 1969-2010. The year refers to the December. Changes that are statistically significant at the $<5 \%$ level are outlined in yellow.

the much reduced gradient of the orange SAT trend line versus the red line in Fig. 3. It can be seen that the cooling described in TS02 and elsewhere was principally a result of the predominantly negative SAT anomalies that occurred during the 1990s.

To examine how well this combined time series reflects East Antarctic SAT anomalies as a whole, Table 1 shows the mean temperature anomalies for the nine individual stations in the consecutive decades of 19912000 and 2001-10 for the austral summer and autumn combined (December-May), and summer and autumn seasons separately, as compared to the mean temperature from 1971-2000 derived for a similar seasonal period. It demonstrates that all the East Antarctic stations were, on average, warmer in 2001-10 as compared to the previous decade for the combined summer/autumn period, with no single station dominating the time series. The SAT difference between the two decades ranges from $0.26^{\circ}-0.80^{\circ} \mathrm{C}$, with a mean value of $0.52^{\circ} \mathrm{C}$. All stations show warmer temperatures in 2001-10 for the summer season alone and again in autumn other than Dumont D'Urville. The sign of the anomalies indicate that at most stations the 1991-2000 period had negative temperature anomalies of greater magnitude than the positive anomalies of the following decade in summer/ autumn (cf. Fig. 3) and summer, primarily due to a cold summer in 2007/08, while the opposite is true in austral autumn. In the combined time series the SAT difference between the two decades is slightly greater in autumn $\left(0.61^{\circ} \mathrm{C}\right)$ than summer $\left(0.44^{\circ} \mathrm{C}\right)$.
Given the continental spatial pattern of the STR described previously, we would expect the primarily positive SAT anomalies during the 2001-10 period to be associated with a negative SAM. However, in 9 of these 10 years the combined summer/autumn SAM has positive values, albeit it of much smaller magnitude than during the majority of the 1990s (Fig. 4). Therefore, there has

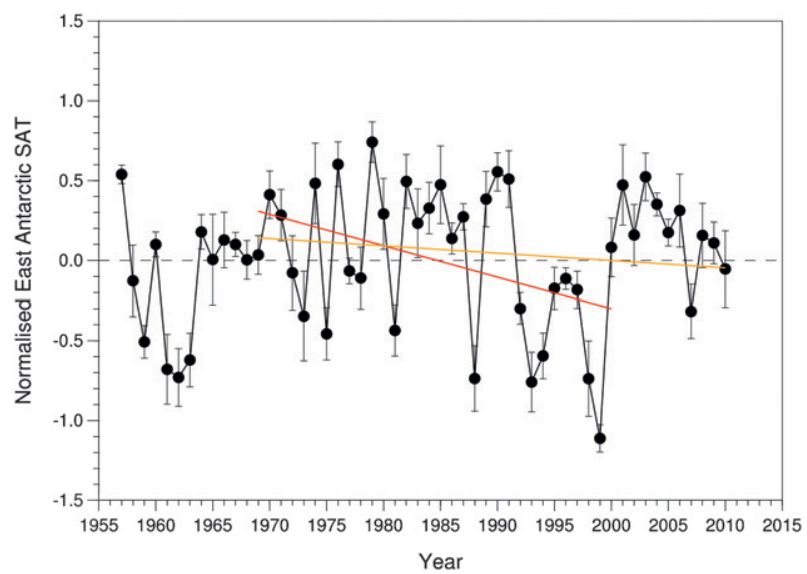

FIG. 3. Time series of an index of normalized summer/autumn East Antarctic SAT derived from nine meteorological stations. The period of normalization is 1971-2000. The vertical lines represent the standard deviation of the annual normalized SAT anomaly across the nine stations. The red and orange lines represent the SAT trends from 1969-2000 and 1969-2010, respectively, which are the equivalent time periods used in Figs. $2 a$ and $2 b$, respectively. 
TABLE 1. Mean East Antarctic station temperature anomalies $\left({ }^{\circ} \mathrm{C}\right)$ for $1991-2000$ and $2001-10$ for austral summer and autumn. The anomalies are derived from a base period of 1971-2000.

\begin{tabular}{|c|c|c|c|c|c|c|}
\hline \multirow[b]{2}{*}{ Station } & \multicolumn{2}{|c|}{ Summer/autumn } & \multicolumn{2}{|c|}{ Summer } & \multicolumn{2}{|c|}{ Autumn } \\
\hline & 1991-2000 & 2001-10 & 1991-2000 & 2001-10 & 1991-2000 & $2001-10$ \\
\hline Amundsen-Scott & -0.37 & 0.43 & -0.42 & 0.48 & -0.38 & 0.46 \\
\hline Casey & -0.52 & 0.00 & -0.58 & -0.16 & -0.48 & 0.22 \\
\hline Davis & -0.18 & 0.36 & -0.14 & 0.19 & -0.15 & 0.55 \\
\hline Dumont D'Urville & -0.47 & -0.16 & -0.53 & -0.02 & -0.33 & -0.36 \\
\hline Mawson & -0.33 & 0.15 & -0.42 & -0.19 & -0.11 & 0.46 \\
\hline Mirny & -0.40 & 0.33 & -0.42 & 0.15 & -0.39 & 0.55 \\
\hline Novolazarevskaya & -0.25 & 0.01 & -0.32 & -0.09 & -0.20 & 0.12 \\
\hline Syowa & -0.26 & 0.11 & -0.22 & 0.14 & -0.24 & 0.13 \\
\hline Vostok & -0.19 & 0.40 & -0.11 & 0.21 & -0.31 & 0.61 \\
\hline All stations & -0.33 & 0.19 & -0.35 & 0.09 & -0.30 & 0.31 \\
\hline
\end{tabular}

been a reversal of the previous STR in East Antarctica during most years in the twenty-first century: only in 2005 (negative SAM, positive SAT anomaly), and 2007 and 2010 (positive SAM, negative SAT anomaly) did a "standard" negative STR exist. This is confirmed by examining the running 11-yr correlation between the East Antarctic temperature series and the SAM (red line in Fig. 4), which shows a much weaker (and statistically insignificant) relationship in the last 11 yr (200010) than at any other time during the period of observations. This is further evident in a reduction of the (negative) magnitude of the summer/autumn STR correlation in East Antarctica from 0.81 for 1957-2000 to 0.72 for 1957-2010.

The marked change in the regional STR during the first decade of the twenty-first century is examined further in Fig. 5, which is a scatterplot of the SAM versus East Antarctic SAT anomaly with the data subdivided by decade. There are only $9 \mathrm{yr}$ (out of the $54 \mathrm{yr}$ of observations) when a positive SAM has been associated

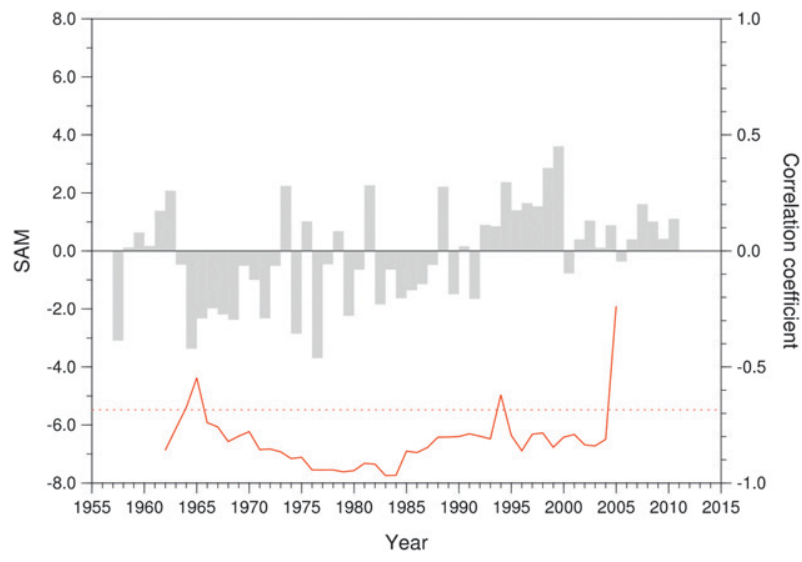

FIG. 4. The summer/autumn SAM (bar graph) and running 11-yr correlation coefficient between the SAM and the normalized East Antarctic SAT (red line). The dashed line is the $1 \%$ statistical significance level. with a positive SAT anomaly in East Antarctica and 7 of those years occurred during the twenty-first century (red dots). Although the exact location of the origin of this plot is dependent on the period of normalization used, it is clear that the STR in the majority of the twenty-first century summer/autumn periods is similar (the red dots are clustered closely together) and their STR is different from that in most other years.

Figure 5 also helps explain why the running 11-yr correlation in Fig. 4 only reduces significantly in magnitude for the final $11 \mathrm{yr}$ examined (2000-10). This is because the strongly positive SAM and standard (i.e., negative) STR during the majority of the 1990s (orange dots) mean that a correlation calculated using running 11 -yr periods combining years from the 1990s and 2000s will still be significantly negative. In particular, at the end of the 1990s, 1998 and 1999 are the two years in the record when the SAM was most positive and East

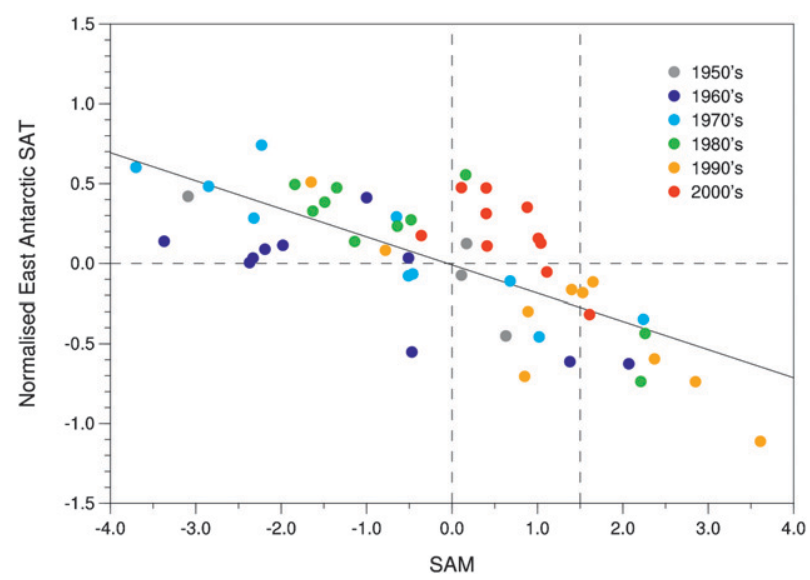

FIG. 5. Scatterplot showing the summer/autumn SAM vs the normalized East Antarctic SAT anomaly. Each colored dot represents a decade (see key). The vertical lines, when the SAM equals 0.0 and 1.5 , are the limits defining the summer/autumn years used in the subsequent difference plots (see also Table 1 ). The correlation for $1957-2010(n=54)$ is -0.72 , significant at the $<1 \%$ level. 
TABLE 2. Years used to produce the difference plots (Figs. 6-8). The year refers to the December of the summer/autumn period.

\begin{tabular}{ll}
\hline \hline & \multicolumn{1}{c}{ Years } \\
\hline Reversed STR & $1990,2001,2002,2003$, \\
& $2004,2006,2008$, and 2009 \\
Standard STR & $1992,1993,1995,1997$, and \\
& 2010 \\
\hline
\end{tabular}

Antarctic temperatures coldest during the summer/ autumn period. This figure also demonstrates why the last point of the running correlation in Fig. 4, while not statistically significant, is still negative as the distribution of the red dots shows that within the 2000-10 period there still exists a negative STR. Finally, Fig. 5 establishes that STR reversals only occur when the magnitude of the SAM is relatively small (e.g., $<1.2$ ), as was generally the case in the first decade of the twenty-first century.

To understand the changes in atmospheric circulation that caused the reversal in this sign of the STR we utilize Fig. 5 to define two sets of years when the summer/ autumn had a similar positive SAM value (0.0-1.5) but the East Antarctic SAT anomaly was of opposite sign. We only examine years from 1979 onward, which is when the ERA-Interim reanalysis begins. This provides 5 years when the standard STR existed and 8 years when the reversed STR occurred (see Table 2). The difference plots (Figs. 6-8) show the mean of the reversed years minus the mean of the standard years.

In Fig. 6 we show the difference in summer/autumn $500-\mathrm{hPa}$ geopotential height, which indicates higher pressure over all of East Antarctica in years when the STR is reversed. For these years a small positive height anomaly is observed over part of East Antarctica (not shown), as compared to the mean for 1979-2010. This is in contrast to the negative anomaly above other regions of the continent, which in the standard STR years is observed across the whole of Antarctica. The pressure difference across much of this area is statistically significant at the $<5 \%$ level (cf. Fig. 6). Examining the individual seasons (not shown) reveals that the anomalous ridging pattern is present in both summer and autumn but that the latter season shows a much greater difference, with values exceeding $50 \mathrm{~m}$. This pressure pattern will lead to increased advection of relatively warm maritime air into the majority of East Antarctica during periods of reversed STR, with Dumont d'Urville being the only coastal station likely to experience enhanced offshore flow along the eastern flank of the pressure anomaly. This may explain why it had a negative SAT anomaly in summer/autumn 2001-10 (cf. Table 1). In addition, the height anomaly is consistent with an increase in katabatic flow at the two inland stations:

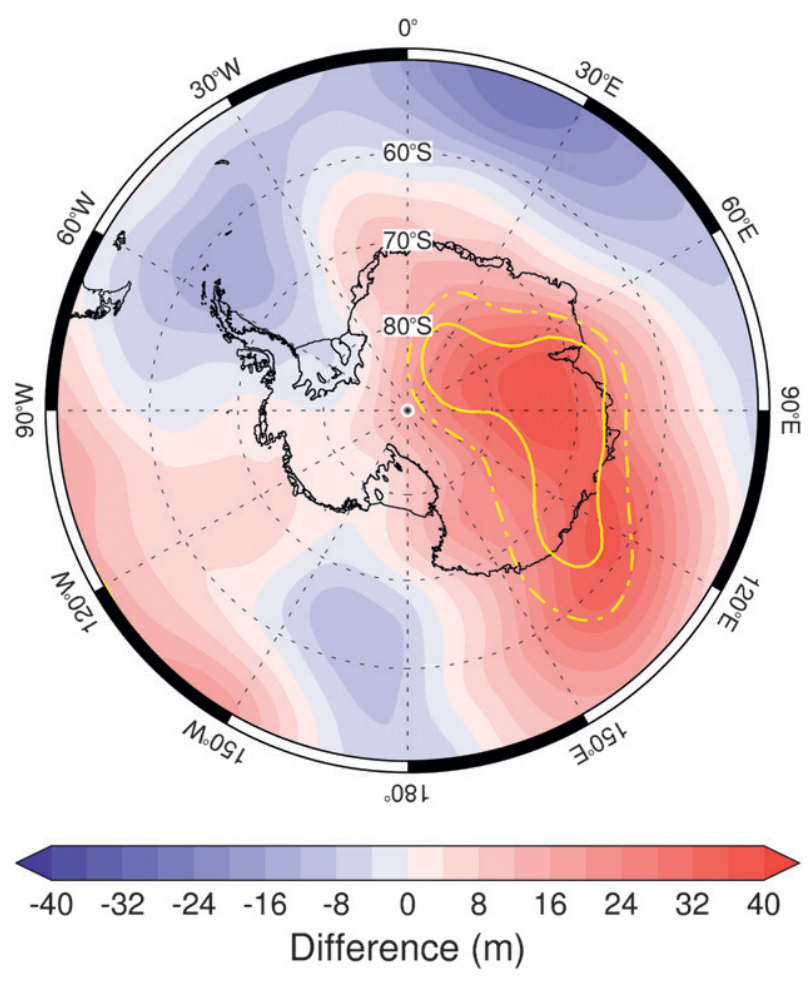

FIG. 6. Difference in 500-hPa geopotential height between years when the summer/autumn SAM has a positive relationship with East Antarctic temperatures minus those when it is negative (see Table 1). The yellow lines represent regions where the difference is statistically significant at the $<5 \%$ (dashed line) and $<1 \%$ (solid line) levels.

Amundsen-Scott and Vostok. Both these processes will give rise to warmer SATs across most of East Antarctica, as shown in Fig. 7: the average SAT difference across East Antarctica is $\sim 1^{\circ} \mathrm{C}$, which is statistically significant at the $<5 \%$ level over much of the region. The greatest SAT differences $\left(>2.5^{\circ} \mathrm{C}\right)$ are located predominantly in the coastal regions on the western flank of the pressure anomaly and generally correspond to those longitudes where the onshore meridional wind component strengthens most during years with reversed STR (not shown).

The impact of the anomalous ridge on the total meridional energy flux toward Antarctica (across the $60^{\circ} \mathrm{S}$ latitude circle) is shown in Fig. 8. Statistically significant increases in poleward (equatorward) energy transport for those summer/autumn periods with reversed STR relative to standard STR can be observed at $\sim 100^{\circ} \mathrm{E}$ $\left(\sim 150^{\circ} \mathrm{E}\right)$, on the western (eastern) flanks of the pressure anomaly where the meridional wind anomalies are greatest. We note that the majority of these anomalies are present throughout the troposphere and into the lower stratosphere. A zonal wavenumber 3 (ZW3) pattern is evident in the difference in the total energy 

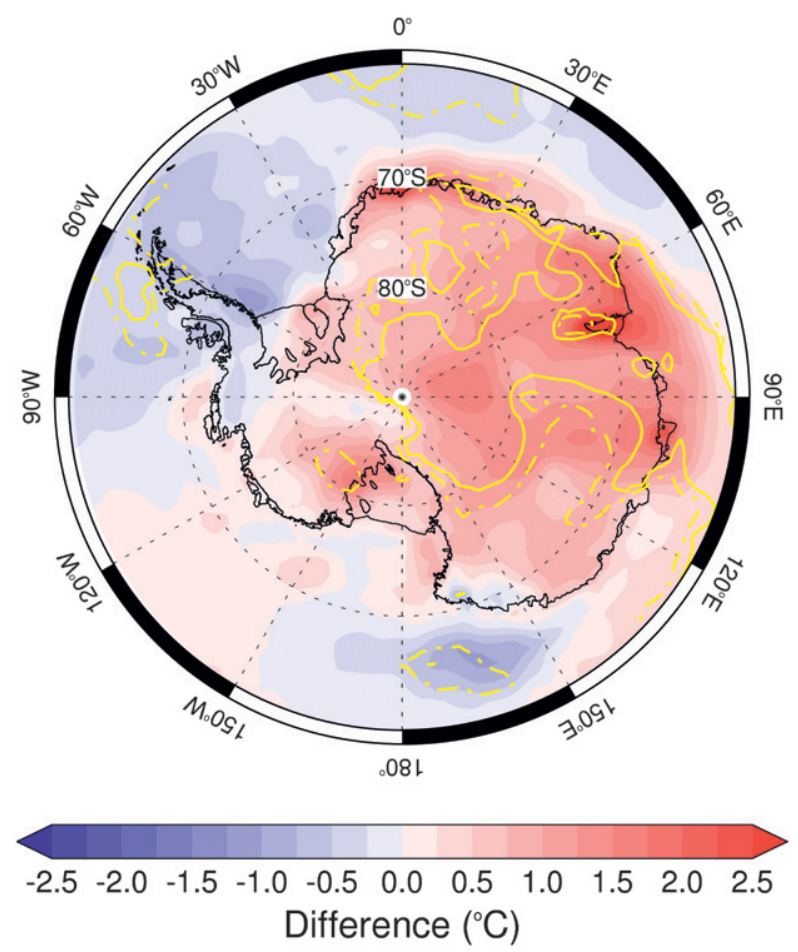

FIG. 7. As in Fig. 6, but showing SAT.

flux, consistent with this mode of atmospheric circulation variability having a significant impact on the meridional flow of energy in and out of Antarctica (e.g., Raphael 2007). Analysis of the individual components (not shown) reveals that the meridional energy flux is dominated by sensible heat, with geopotential energy making a small contribution above $\sim 500 \mathrm{hPa}$ while the contribution from latent heat is negligible in both the troposphere and lower stratosphere. Thus, the surface warming appears to be predominantly a result of advection of warmer air into the region, and this is also suggested by the warming above East Antarctica being of similar magnitude throughout the troposphere. Climatologically, there is a low centered at $\sim 100^{\circ} \mathrm{E}$ at sea level (cf. Fig. 7 of Marshall et al. 2011) with a trough at upper levels. Examining the mean summer/autumn $500-\mathrm{hPa}$ geopotential height fields for years with reversed and standard STR separately (not shown) reveals that the increase in poleward energy flux between $40^{\circ}$ and $135^{\circ} \mathrm{E}$ in the former is due to both a $10^{\circ}$ westward shift of the 500-hPa climatological trough from $100^{\circ}$ to $90^{\circ} \mathrm{E}$ and the almost complete disappearance of the ridge between this trough and the climatological trough to the west at $20^{\circ} \mathrm{E}$. Thus, decadal variability in the ZW3 pattern (Reason 2000), in terms of changes in both its amplitude and phase in the East Antarctic region, was a key component in the formation of the anomalous ridge pattern associated with the reversed STR.

\section{Discussion and conclusions}

We have demonstrated that the spatial pattern of the austral summer/autumn STR across the Antarctic continent, as described in TS02 and many subsequent papers, is not temporally invariant. In the first decade of the twenty-first century the sign of the STR over almost all of East Antarctica changed from predominantly negative to positive, even though the seasonal SAM remained mainly positive throughout (Fig. 5). Note that the contemporaneous recent cooling in the Antarctic Peninsula (e.g., McGrath and Steffen 2012) is also inconsistent with the TS02 STR. Previously, only STR reversals on much smaller spatial scales have been identified (e.g., Silvestri and Vera 2009; Marshall et al. 2011). The large-scale reversal appears to be primarily a response to an anomalous circulation pattern over East Antarctica, resulting from variability in the phase and amplitude of ZW3. In years when there is a reversed STR a ridge of anomalous high pressure is located over all of East Antarctica (Fig. 6), such that, taken as a whole, there is greater energy flux into the region (Fig. 8). In addition to the advection of greater heat into much of the East Antarctic coastal region, this situation leads to an enhancement of the katabatic drainage across parts of the interior of the continent, which disrupts the surface temperature inversion leading to warmer SATs inland. The average summer/autumn SAT increase across East Antarctica for years with reversed versus standard STR is $\sim 1^{\circ} \mathrm{C}$ (Fig. 7).

This circulation pattern associated with the reversed STR is analogous to the East Antarctic ridging pattern described by Cullather et al. (1996), who examined annual data. These authors described how this feature was responsible for an anticorrelation between the Southern Oscillation index and West Antarctic moisture convergence in the early 1990s. Its presence or lack of it has an influence on the climatological Amundsen Sea low (e.g., Turner et al. 2013), which strongly influences the climate of West Antarctica and the Antarctic Peninsula by controlling the meridional component of the large-scale circulation in the Amundsen/Bellingshausen Sea sector. The interplay between these two components of the ZW3 is likely to play a significant role in producing the opposite temperature responses to the SAM in the Antarctic Peninsula and East Antarctica (e.g., Fig. 2).

Similar to SAT, coastal Antarctic precipitation is also strongly modulated by the meridional wind component. For example, van Ommen and Morgan (2010) showed that there is no significant correlation between precipitation at Law Dome $\left(66^{\circ} 46^{\prime} \mathrm{S}, 112^{\circ} 48^{\prime} \mathrm{E}\right)$ and the SAM. However, they did find a significant relationship with an "Australian sector" ZW3 index. Given that Law 


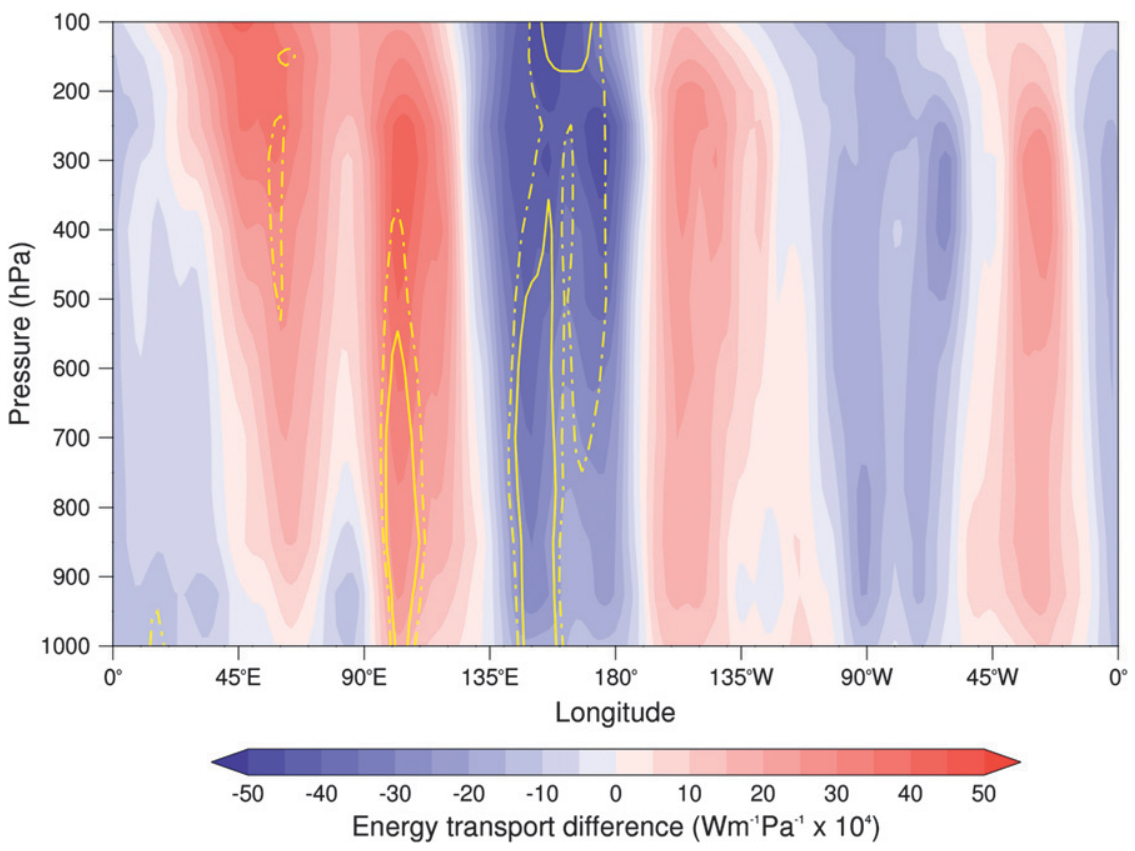

FIG. 8. As in Fig. 6, but showing the difference in the longitude-pressure distribution of the total energy flux across $60^{\circ} \mathrm{S}$. Positive (red) values indicate a poleward flux and negative (blue) values an equatorward flux. The yellow lines represent regions where the difference is statistically significant at the $<10 \%$ (dashed line) and $<5 \%$ (solid line) levels.

Dome is located on the western edge of the anomalous ridge pattern (Fig. 6), it seems likely that the circulation changes associated with the changing STR will also be responsible for the precipitation variability at this coastal site. Turner et al. (2009) examined austral autumn 500-hPa trends for 1979-2006 from ECMWF data and output from coupled climate models from the Intergovernmental Panel on Climate Change (IPCC) Fourth Assessment Report (AR4). The former showed a trend toward the ridge structure seen in Fig. 6, while the mean of the models actually showed greater troughing in this region (cf. Figs. 3a and 3c, respectively, of Turner et al. 2009). All the IPCC AR4 models are forced using observed changes in greenhouse gases and tropospheric sulfate aerosols and the majority also include stratospheric forcing through ozone depletion and volcanic aerosols. The models actually do a reasonable job at simulating ZW3 with respect to its spatial pattern and temporal variability; hence, the fact that they fail to reproduce the observed trend suggests that the regional ZW3 variability is unlikely to be anthropogenically forced (Raphael and Holland 2006), and, therefore, neither is the observed STR variability that it impacts. This conclusion was also reached by Marshall et al. (2011), who used SAM reconstructions and ice core-derived oxygen-isotope data to demonstrate marked STR variability throughout the twentieth century in another part of East Antarctica. Further evidence for a natural driver of the recent STR reversal is that the ridge structure is more pronounced in austral autumn, when the impact of anthropogenic forcing on SH extratropical climate variability is much weaker than during summer (e.g., Thompson et al. 2011).

The fact that STR variability appears to be most likely due to natural internal climate circulation variability and occurs on decadal time scales has consequences for our understanding of past and future Antarctic climate. For example, it implies that we are unlikely to be able to derive a clear proxy for the SAM from the Antarctic ice core record (e.g., Schneider et al. 2006), even from sites in the continental interior. It also indicates that predictions of future trends in the SAM-generally negative in austral summer (as stratospheric ozone recovers) and positive in other seasons (Perlwitz et al. 2008; Son et al. 2008; Thompson et al. 2011)—will not necessarily be associated with Antarctic SAT changes that reflect the assumed paradigm of the spatial pattern of the STR across Antarctica described by TS02, unless they result in consistently strong SAM events. For example, we cannot necessarily expect a more positive SAM to always mask the effects of global warming in East Antarctica; indeed, there may be periods in the future when a relatively weak positive SAM actually acts to amplify temperature increases across this region. 
Acknowledgments. This work was supported by the U.K. Natural Environment Research Council through the British Antarctic Survey research programme Polar Science for Planet Earth. We thank the three reviewers for their constructive comments that helped improve the final manuscript.

\section{REFERENCES}

Bracegirdle, T. J., and G. J. Marshall, 2012: The reliability of Antarctic tropospheric pressure and temperature in the latest global reanalyses. J. Climate, 25, 7138-7146.

Bromwich, D. H., and R. L. Fogt, 2004: Strong trends in the skill of the ERA-40 and NCEP-NCAR reanalyses in the high and midlatitudes of the Southern Hemisphere, 1958-2001. J. Climate, 17, 4603-4619.

_ - J. P. Nicolas, and A. J. Monaghan, 2011: An assessment of precipitation changes over Antarctica and the Southern Ocean since 1989 in contemporary global reanalyses. $J$. Climate, 24, 4189-4209.

Comiso, J. C., 2000: Variability and trends in Antarctic surface temperatures from in situ and satellite infrared measurements. J. Climate, 13, 1674-1696.

Cullather, R. I., D. H. Bromwich, and M. L. van Woert, 1996: Interannual variations in Antarctic precipitation related to El Niño-Southern Oscillation. J. Geophys. Res., 101 (D14), 19 109-19 118.

Dee, D. P., and Coauthors, 2011: The ERA-Interim reanalysis: Configuration and performance of the data assimilation scheme. Quart. J. Roy. Meteor. Soc., 137, 553-597.

Fogt, R. L., J. Perlwitz, A. J. Monaghan, D. H. Bromwich, J. M. Jones, and G. J. Marshall, 2009: Historical SAM variability. Part II: Twentieth-century variability and trends from reconstructions, observations, and the IPCC AR4 models. J. Climate, 22, 5346-5365.

Genthon, C., and G. Krinner, 1998: Convergence and disposal of energy and moisture on the Antarctic polar cap from ECMWF reanalyses and forecasts. J. Climate, 11, 1703-1716.

Gillett, N. P., D. A. Stone, P. A. Stott, T. Nozawa, A. Y. Karpechko, G. C. Hegerl, M. F. Wehner, and P. D. Jones, 2008: Attribution of polar warming to human influence. Nat. Geosci., 1, 750-754.

Jones, J. M., R. L. Fogt, M. Widmann, G. J. Marshall, P. D. Jones, and M. Visbeck, 2009: Historical SAM variability. Part I: Centurylength seasonal reconstructions. J. Climate, 22, 5319-5345.

Kwok, R., and J. C. Comiso, 2002: Spatial patterns of variability in Antarctic surface temperature: Connections to the Southern Hemisphere annular mode and the Southern Oscillation. Geophys. Res. Lett., 29 (14), doi:10.1029/2002GL015415.

Marshall, G. J., 2003: Trends in the southern annular mode from observations and reanalyses. J. Climate, 16, 4134-4143.

— 2007: Half-century seasonal relationships between the southern annular mode and Antarctic temperatures. Int. J. Climatol., 27, 373-383.

— S. Di Battista, S. S. Naik, and M. Thamban, 2011: Analysis of a regional change in the sign of the SAM-temperature relationship in Antarctica. Climate Dyn., 36, 277-287.

McGrath, D., and K. Steffen, 2012: Recent cooler conditions on the northern Antarctic Peninsula. Bull. Amer. Meteor. Soc., 93, S154-S155.
Parish, T. R., and D. H. Bromwich, 2007: Reexamination of the near-surface airflow over the Antarctic continent and implications on atmospheric conditions at high southern latitudes. Mon. Wea. Rev., 135, 1961-1973.

Perlwitz, J., S. Pawson, R. L. Fogt, J. E. Nielsen, and W. D. Neff, 2008: Impact of stratospheric ozone recovery on Antarctic climate. Geophys. Res. Lett., 35, L08714, doi:10.1029/2008GL033317.

Raphael, M. N., 2007: The influence of atmospheric zonal wave three on Antarctic sea ice variability. J. Geophys. Res., 112, D12112, doi:10.1029/2006JD007852.

_ , and M. M. Holland, 2006: Twentieth century simulation of the southern hemisphere climate in coupled models. Part I: Large scale circulation variability. Climate Dyn., 26, $217-$ 228.

Reason, C. J. C., 2000: Multidecadal climate variability in the subtropics/mid-latitudes of the Southern Hemisphere oceans. Tellus, 52A, 203-223.

Santer, B. D., T. M. L. Wigley, J. S. Boyle, D. J. Gaffen, J. J. Hnilo, D. Nychka, D. E. Parker, and K. E. Taylor, 2000: Statistical significance of trends and trend differences in layer-average atmospheric temperature time series. J. Geophys. Res., 105 (D6), 7337-7356.

Schneider, D. P., E. J. Steig, and J. C. Comiso, 2004: Recent climate variability in Antarctica from satellite-derived temperature data. J. Climate, 17, 1569-1583.

$\longrightarrow,-$ T. D. van Ommen, D. A. Dixon, P. A. Mayewski, J. M. Jones, and C. M. Bitz, 2006: Antarctic temperatures over the past two centuries from ice cores. Geophys. Res. Lett., 33, L16707, doi:10.1029/2006GL027057.

Silvestri, G., and C. Vera, 2009: Nonstationary impacts of the southern annular mode on Southern Hemisphere climate. J. Climate, 22, 6142-6148.

Son, S.-W., and Coauthors, 2008: The impact of ozone recovery on the Southern Hemisphere westerly jet. Science, 320, 14861489 .

Thompson, D. W. J., and S. Solomon, 2002: Interpretation of recent Southern Hemisphere climate change. Science, 296, 895 899.

P. J. Kushner, M. H. England, K. M. Grise, and D. J Karoly, 2011: Signatures of the Antarctic ozone hole in Southern Hemisphere surface climate change. Nat. Geosci., 4, 741-749.

Turner, J., and Coauthors, 2004: The SCAR READER project: Toward a high-quality database of mean Antarctic meteorological observations. J. Climate, 17, 2890-2898.

— , and Coauthors, 2009: Non-annular atmospheric circulation change induced by stratospheric ozone depletion and its role in the recent increase of Antarctic sea ice extent. Geophys. Res. Lett., 36, L08502, doi:10.1029/2009GL037524.

_- T. Thillips, J. S. Hosking, G. J. Marshall, and A. Orr, 2013: The Amundsen Sea low. Int. J. Climatol., 33, 18181829.

van den Broeke, M. R., and N. P. M. van Lipzig, 2003: Response of wintertime Antarctic temperatures to the Antarctic Oscillation: Results of a regional climate model. Antarctic Peninsula Climate Variability: Historical and Paleoenvironmental Perspectives, E. Domack et al., Eds., Antarctic Research Series, Vol. 79, Amer. Geophys. Union, 43-58.

van Ommen, T. D., and V. Morgan, 2010: Snowfall increase in coastal East Antarctica linked with southwest Western Australian drought. Nat. Geosci., 3, 267-272. 